\title{
Macroalgas Como Co-sustratos en Procesos de Digestión Anaerobia de Purines de Cerdo
}

\section{Macroalgae as Co-Substrates in Anaerobic Digestion Processes of Pig Slurry}

Presentación: 06/10/2020

\section{Doctorando:}

\section{Marcos Astorga}

Grupo de Investigación Ingeniería Química Aplicada a Bioprocesos, Facultad Regional del Neuquén, Universidad Tecnológica Nacional - Argentina

marcos.ad.as@gmail.com

\section{Director/es:}

\section{Marcela Gatti}

\section{Co-director/es:}

\section{Alberto Camacho}

\section{Resumen}

La Digestión Anaerobia (DA) ha demostrado ser muy útil para el tratamiento de efluentes con alta carga orgánica y la generación de metano. A su vez, el empleo de co-sustratos incrementa el rendimiento de metano en la DA, los cuales pueden traducirse en beneficios tanto medioambientales, como económicos. En este trabajo de investigación se llevó a cabo la comparación de rendimientos metanogénicos de tres co-sustratos en la DA de purines de cerdo: macroalga, plantas acuáticas y planta terrestre. Para ello se empleó la determinación del Potencial Bioquímico de Metano (PBM). Los resultados muestran que empleando macroalga como co-sustrato, se logran obtener $157,2 \pm 66,1 \mathrm{mlCH}_{4} / \mathrm{gSV}$, alrededor de tres veces el volumen de metano obtenido comparándolo con una DA utilizando solamente purín de cerdo. De esta manera se propone la utilización de macroalgas para incrementar el rendimiento metanogénico en procesos de DA.

Palabras clave: Digestión Anaerobia, Purín de Cerdo, Tratamiento de Efluentes, Potencial Bioquímico de Metano, Algas

\begin{abstract}
Anaerobic Digestion (AD) has proven to be very useful for the treatment of effluents with high organic load and the generation of methane. At the same time, the use of co-substrates increases the yield of methane in $\mathrm{AD}$, which can be translated into both environmental and economic benefits. In this research, the comparison of methanogenic yields of three co-substrates in the $\mathrm{AD}$ of pig manure was carried out: macroalgae, aquatic plants and terrestrial plant. In order to do this, Biochemical Methane Potential (BMP) determination was performed. The results show that using macroalgae as a co-substrate, it is possible to obtain $157,2 \pm 66,1 \mathrm{mlCH}_{4} / \mathrm{gVS}_{\text {, around }}$ three times the volume of methane obtained comparing it with an AD using only pig slurry. Thus, the use of macroalgae is proposed to increase methanogenic yield in $\mathrm{AD}$ processes.
\end{abstract}

Keywords: Anaerobic Digestion, Pig Slurry, Effluent Treatment, Biochemical Methane Potential, Algae 


\section{Introducción}

Durante las últimas décadas se ha observado en la provincia del Neuquén, un aumento en la producción porcina debido a diversos factores socio-económicos (Organización de las Naciones Unidas para la Alimentación y la Agricultura, 2015). A su vez, esta actividad trae aparejado un incremento en la generación de efluentes porcinos que tienen un elevado impacto negativo en el ambiente si no son tratados de manera adecuada. Lamentablemente, es común observar la disposición final de purines de cerdo como fertilizantes , o en el peor de los casos almacenados en piletones al aire libre (Barrionuevo et al., 2019). Estas prácticas pueden llegar a ser contraproducentes para aguas superficiales y subterráneas, además de emitir molestos olores y contribuir a la emisión de gases nocivos para la salud y el ambiente (BREF, 2003; Scotford et al., 1999; Moral et al., 2005).

Considerando las concentraciones promedio de materia orgánica, especies de nitrógeno y fósforo presentes en los purines de cerdo, resulta interesante contemplarlas como sustratos para procesos de DA. De esta manera se puede transformar una forma de energía que tiene una manipulación compleja, en algo más simple de transportar y utilizar como puede ser el gas metano. Además, el efluente generado en la DA, es más estable que el afluente en términos microbianos, tiene una reducida carga orgánica, y una concentración de nutrientes considerablemente menor. Por lo tanto, la DA permite transformar un residuo altamente contaminante en corrientes con gran valor agregado (Nizami et al., 2019).

Se ha observado que al incorporar co-sustratos a procesos de DA, el rendimiento metanogénico se incrementa. Por ejemplo, Rodríguez-Abalde et al, (2016) estudiaron la co-digestión de mezclas de dos subproductos animales, purín de cerdo y residuos pasteurizados de mataderos, con glicerina en modo de cultivo continuo y en condiciones mesofílicas. Lograron incrementar 2,9 veces la producción de metano y 1,8 veces el rendimiento de eliminación de materia orgánica respecto al proceso de DA de purín solo. Algo similar ocurre cuando se emplean algas como co-sustratos. Miao et al. (2014) observaron una duplicación en el rendimiento de metano al duplicar la relación inóculo-sustrato, y no registraron problemas de inhibición por pH, acumulación de ácidos grasos volátiles ni nitrógeno amoniacal.

El objetivo principal del presente estudio es comparar de manera cuantitativa el rendimiento metanogénico de tres co-sustratos en procesos de DA de purines de cerdo: i) macroalga, ii) mezcla de plantas acuáticas, iii) planta terrestre. Para ello se propone emplear la determinación del Potencial Bioquímico Metanogénico (PBM), utilizando dispositivos de diseño y fabricación casera.

\section{Desarrollo}

\section{Determinaciones Analiticas}

Las siguientes determinaciones se realizaron según los protocolos de APHA (2012): pH, conductividad $(\Lambda)$, sólidos totales (ST), sólidos volátiles (SV), alcalinidad total (AT), alcalinidad parcial (AP).

\section{Inóculo}

Durante el presente trabajo se utilizó un inóculo preparado en laboratorio tomando como referencia estudios de Cong et al. (2018) y Hosseini Koupaie et al. (2019). El inóculo se preparó utilizando restos de purín de cerdo de determinaciones previas. Se empleó un biorreactor de construcción casera de $6 \mathrm{~L}$ de capacidad total, el cual se llenó hasta los $4 \mathrm{~L}$ con los restos mencionados anteriormente. Se llevó a cabo un proceso semicontinuo a temperatura mesofílica de $35^{\circ} \mathrm{C}$. Para alimentar al biorreactor se utilizó purín de cerdo ( $\mathrm{pH}=[7,00-8,20]$; $\mathrm{ST}=10,5 \% \mathrm{p} / \mathrm{p} ; \mathrm{SV}=2,4 \% \mathrm{p} / \mathrm{p}$ ) recolectado de una chacra de Plottier, Neuquén, reemplazando $400 \mathrm{ml}$ de la mezcla cada 8 a 10 días, o cuando la producción de metano diaria fuera igual o menor que 50ml/día. El biorreactor alcanzó una producción de metano estable promedio de 100 $\mathrm{ml} /$ día, y se mantuvo en esas condiciones durante 6 meses antes de utilizarlo como inóculo en la determinación de PBM. El inóculo fue caracterizado y se 
obtuvieron los siguientes valores: $\mathrm{pH}=7,13 ; \Lambda=22,0 \mathrm{mS} ; \mathrm{AT}=2607,1 \pm 113 \mathrm{mgCaCO} / \mathrm{L}(\mathrm{n}=2) ; \mathrm{AP}=1850 \pm 213$ $\mathrm{mgCaCO} / \mathrm{L}(\mathrm{n}=2) ; \mathrm{ST}=10,2 \pm 0,3 \% \mathrm{p} / \mathrm{p}(\mathrm{n}=3)$ y $\mathrm{SV}=2,0 \pm 0,4 \% \mathrm{p} / \mathrm{p}(\mathrm{n}=3)$.

\section{Muestreo y Caracterización de Sustrato y Co-Sustratos}

Se empleó purín de cerdo como sustrato en la determinación de PBM. El mismo fue recolectado de una chacra familiar ubicada en la ciudad de Plaza Huincul, Neuquén siguiendo las recomendaciones de Peters et al. 2003. Las caracterización química del purín de cerdo se llevó a cabo por duplicado $(n=2): p H=7,67 \pm 0,04$; $\Lambda=8,93 \pm 0,37 \mathrm{mS} ; \mathrm{SV}=2,01 \pm 0,11 \% \mathrm{p} / \mathrm{p}$.

Como se mencionó en la introducción, se estudiaron tres co-sustratos que pueden encontrarse en la zona centro de la provincia de Neuquén. La macroalga verde filamentosa fue identificada mediante microscopía óptica como Spirogyra sp. Por otro lado, la mezcla de plantas acuáticas estaba compuesta por dos especies, Azolla sp. y Salvinia molesta. Tanto la macroalga como las plantas acuáticas fueron recolectadas a orillas del Río Limay en la ciudad de Neuquén. Finalmente, se utilizaron restos de poda de Prunus armeniaca (árbol de damascos), recolectado de una chacra ubicada en la ciudad de Plaza Huincul. Todos los co-sustratos fueron reducidos a fragmentos de tamaño homogéneos empleando un cutter.

\section{Potencial Bioquímico Metanogénico (PBM)}

La determinación de PBM de purín de cerdo con los tres co-sustratos se llevó a cabo siguiendo las sugerencias de Holliger et al. (2016). Se utilizaron biorreactores de vidrio de $150 \mathrm{ml}$ de capacidad total, con un volumen final de $100 \mathrm{ml}$. Las tapas de los biorreactores se modificaron para incorporarles una válvula, a la cual se le conectó una manguera que conectaba el biorreactor con el sistema de recolección de biogás. Para ese último sistema, se emplearon jeringas, en las cuales su émbolo se desplazaba a medida que el biogás se iba generando. Una vez realizada la lectura del volúmen de biogás, este se hacía burbujear en un sistema de vaso invertido con solución de $\mathrm{NaOH} 1 \mathrm{~N}$ para solubilizar el dióxido de carbono. De esta manera, se podía llevar a cabo la lectura del volumen de metano presente en el biogás. La determinación de PBM se realizó por triplicado para las mezclas de sustrato y co-sustratos, y por duplicado en el caso de los controles. Se empleó una relación de inóculo/sustrato (basada en SV) de 0,08 $\pm 0,01(\mathrm{n}=9)$. El ensayo se llevó a cabo durante 40 días a $35^{\circ} \mathrm{C}$, momento en el cual el metano registrado fue el 5\% del registro anterior. Cada biorreactor se llenó con $90,0 \mathrm{ml}$ de sustrato (purín de cerdo), 9,0 $\mathrm{ml}$ de inóculo, 0,1 $\mathrm{ml}$ de solución de micro y macronutrientes (Angelidaki et al., 2009), y co-sustratos de acuerdo a lo que se muestra en la Tabla 1.

\begin{tabular}{|l|l|l|l|}
\hline Mezcla & Co-Sustrato (g) & PH & SV(g) \\
\hline Purín y Macroalga & $5,51 \pm 0,05$ & $7,84 \pm 0,02$ & $1,95 \pm 0,00$ \\
\hline Purín y Plantas Acuáticas & $2,02 \pm 0,02$ & $7,46 \pm 0,04$ & $3,05 \pm 0,01$ \\
\hline Purín y Planta Terrestre & $6,47 \pm 0,06$ & $7,62 \pm 0,11$ & $2,18 \pm 0,00$ \\
\hline Purín (Control) & - & $7,67 \pm 0,04$ & $1,83 \pm 0,01$ \\
\hline
\end{tabular}

Tabla 1: Caracterización inicial de las mezclas de reacción para la determinación de PBM. Los valores indican valores promedios \pm desviación estándar

\section{Resultados}

Como puede observarse en la Tabla 2 y la Figura 1, la macroalga como co-sustrato fue la que produjo mayor cantidad de metano $157,21 \pm 66,10 \mathrm{ml} / \mathrm{gSV}$, seguida de las plantas acuáticas y por último los restos de poda del árbol de damascos. En todos los casos el contenido de metano en el biogás fue mayor al 80\%, indicando una elevada actividad de las arqueas metanogénicas. 


\begin{tabular}{|l|l|l|l|}
\hline Mezclas & Biogás (ml/gSV) & Metano (ml/gSV) & Metano (\%) \\
\hline Purín y Macroalga & $193,33 \pm 51,66$ & $157,21 \pm 66,10$ & $81,91 \pm 9,98$ \\
\hline Purín y Plantas Acuáticas & $67,58 \pm 36,97$ & $59,49 \pm 32,53$ & $88,21 \pm 3,13$ \\
\hline Purín y Planta Terrestre & $55,64 \pm 5,00$ & $46,06 \pm 3,38$ & $83,28 \pm 1,23$ \\
\hline Control & $41,03 \pm 1,57$ & $33,04 \pm 0,32$ & $80,59 \pm 3,88$ \\
\hline
\end{tabular}

Tabla 2: Volúmenes de biogás y metano acumulado, y porcentajes de metano en el biogás, obtenidos en la determinación de PBM a diferentes mezclas de reacción. Los valores indican valores promedios \pm desviación estándar

Considerando los valores de concentración de compuestos lignocelulósicos y de carbohidratos fácilmente fermentables que comúnmente se encuentran en los co-sustratos empleados (Miledge et al., 2019), estos resultados podrían explicarse en términos de disponibilidad de sustratos para los microorganismos presentes en los procesos de DA. A medida que los co-sustratos incrementan su contenido en compuestos lignocelulósicos, más tiempo y recursos necesitarán los microorganismos para poder hidrolizarlos, considerando que poseen las enzimas para ello. Esto se traduciría en menor disponibilidad de sustratos para las bacterias acetogénicas, y por lo tanto menor cantidad de sustratos para las arqueas acetotróficas, finalmente menor producción de metano. Por otro lado, a medida que los co-sustratos posean compuestos que sean fácilmente hidrolizables, más sustrato estará presente para las arqueas y más producción de metano podría observarse (Adekunle et al., 2015).

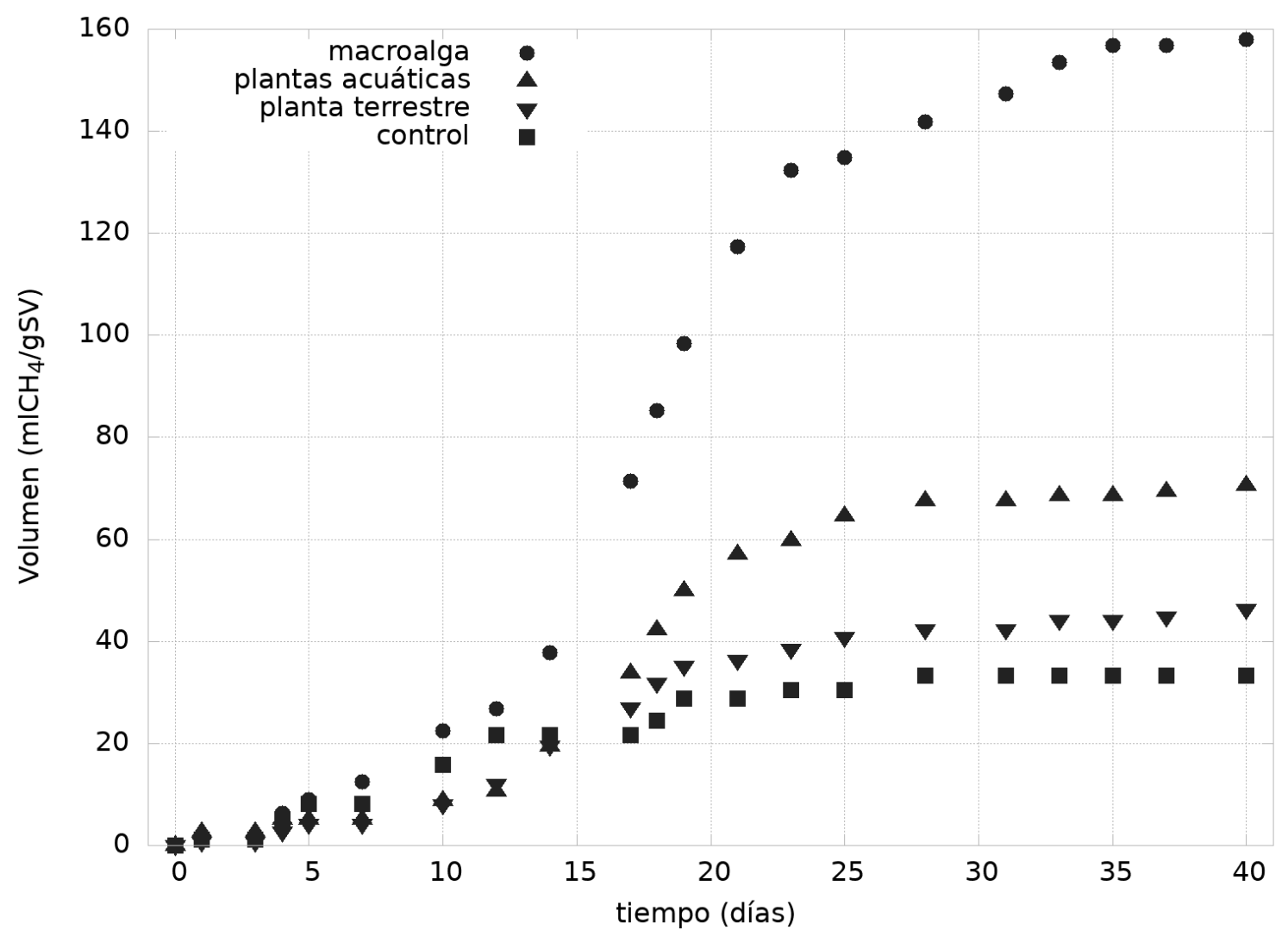

Figura 1: Volumen de metano en base sólidos volátiles en función del tiempo

En la Figura 1 se observa el registro de metano generado durante los 40 días de duración de la determinación de PBM. El comportamiento casi lineal observado durante los primeros 15 días aproximadamente, surge de la baja relación de inóculo/sustrato empleada en este trabajo. Al existir menor concentración de 
microorganismos al comienzo de la determinación, no se genera metano en una cantidad considerable. Esta baja relación I/S solo afecta el tiempo al cual inicia una actividad vigorosa de los microorganismos, no el volumen de metano acumulado según Angelidaki et al. (2009).

De esta manera empleando macroalgas, en particular Spirogyra sp., se puede incrementar significativamente el rendimiento metanogénico en procesos de digestión anaerobia de purines de cerdo.

\section{Referencias}

Adekunle, K. F. y Okolie, J. A. (2015). A review of Biochemical Process of Anaerobic Digestion, Advances in Bioscience and Biotechnology, 6, 205-212. doi:10.4236/abb.2015.63020

Angelidaki, I., Alves, M., Bolzonella, D., Borzacconi, L., Campos, J. L., Guwy, A. J., Kalyuzhnyi, S., Jenicek, P. y van Lier, J. B. (2009). Defining the biomethane potential (BMP) of solid organic wastes and energy crops: a proposed protocol for batch assays, Water Science and Technology, 59(5), 927-934. doi:10.2166/wst.2009.040

APHA (2012). Standard Methods for the Examination of Water and Wastewater, 22nd edition, American Public Health Association, American Water Works Association, Water Environment Federation.

Barrionuevo, M. E., Ejarque, M., Zanovello, L. y Bartucci, S. L. (2019). Prácticas y usos de los residuos pecuarios de productores familiares en un valle de la Patagonia Argentina, Ambiente y Desarrollo, 23(44).

doi:10.11144/Javeriana.ayd23-44.purp

BREF. (2003). Documento de Referencia de Mejores Técnicas Disponibles en la Industria Química Orgánica de Gran Volumen de Producción. Ministerio de Medio Ambiente. España.

Cong, W., Moset, V., Feng, L., Moller, H. B. y Eriksen, J. (2018). Anaerobic co-digestion of grass and forbs: Influence of cattle manure or grass based inoculum, Biomass and Bioenergy, 119, 90-96.

doi:10.1016/j.biombioe.2018.09.009

Hosseini Koupaie, E., Azizi, A., Bazyar Lakeh, A. A., Hafez, H. y Elbeshbishy, E. (2019). Comparison of liquid and dewatered digestate as inoculum for anaerobic digestion of organic solid wastes, Waste Management, 87, 228-236. doi:10.1016/j.wasman.2019.02.014

Miao, H., Wang, S., Zhao, M., Huang, Z., Ren, H., Yan, Q. y Ruan, W. (2014). Codigestion of Taihu blue algae with swine manure for biogas production, Energy Conversion and Management, 77, 643-649. doi:10.1016/j.enconman.2013.10.025

Milledge, J. J., Nielsen, B. V., Maneein, S. y Harvey, P. (2019). A brief review of anaerobic digestion of algae for bioenergy, Energies, 12(6), 1166. doi:10.3390/en12061166

Moral, R., Pérez-Murcia, M. D., Pérez-Espinosa, A., Moreno-Caselles, J. y Paredes, C. (2005). Estimation of nuetrient values of pig slurries in Southeast Spain using easily determined properties, Waste Management, 25, 719-725. doi:10.1016/j.wasman.2004.09.010

Nizami, A. S., Rehan, M., Waqas, M., Naqvi, M., Auda, O. K. M., Shahzad, K., Miandad, R., Khan, M. Z., Syamsiro, M., Ismail, I. M. I. y Pant, D. (2017). Waste Biorefineries: Enabling Circular Economies in Developing Countries, Bioresource Technology, 241, 1101-1117. doi:10.1016/j.biortech.2017.05.097 
Organización de las Naciones Unidas para la Alimentación y la Agricultura. (2015). Documento de Trabajo N. ${ }^{\circ}$ 11: Actividad Pecuaria en la Provincia del Neuquén. Proyecto FAO UTF ARG 017, Desarrollo Institucional para la Inversión.

http://www.fao.org/fileadmin/user_upload/rlc/utf017arg/neuquen/DT_11_Actividad_Pecuaria_Neuquen.pdf

Rodríguez-Abalde, A., Flotats, X. y Fernández, B. (2016). Optimization of the anaerobic co-digestion of pasteurized slaughterhouse waste, pig slurry and glycerine, Waste Management, 61, 521-528.

doi:10.1016/j.wasman.2016.12.022

Scotford, I. M., Cumby, T. R., Richards, P. A., Keppel, D. y Lenehan, J. J. (1999). Development of an in-line nutrient sensing system for livestock slurries. Journal of Agricultural Engineering Research, 74, 303-316. doi:10.1006/jaer.1999.0467 